\title{
Living with FGM: Improving Knowledge and Skills of Health Care Providers in Iraqi Kurdistan
}

Osman Mahmoudi ( $\square$ mahmoudi.osman@gmail.com)

Hamraz Counseling Center of Javanrud

\section{Research}

Keywords: Psychosexual care, physical care, referral program, girls and women living with FGM, TOT workshop

Posted Date: December 13th, 2021

DOI: https://doi.org/10.21203/rs.3.rs-1150973/v1

License: (c) (i) This work is licensed under a Creative Commons Attribution 4.0 International License. Read Full License 


\section{Abstract}

Background: Despite the high prevalence of female genital mutilation in many settings and the health consequences associated with it, many healthcare providers have limited knowledge of female genital mutilation and limited skills for preventing and managing related complications. With Knowledge of this Important matter aim of this study is to determine the effectiveness of TOT workshops on the knowledge and skills of social workers working with girls and women affected by FGM.

Methods: To demonstrate the findings, a quasi-experimental study was conducted with a pre and postassessment. There were 44 participants who worked with FGM victims across Iraqi Kurdistan. Sociodemographic details of the participants who have collected knowledge on psychosexual and physical care, psychosexual skills, and referral programs were assessed using a continuum scale of 0 to 4 . Descriptive and inferential statistics were carried out for the analysis.

Results: The results showed that participants' knowledge and skills improved in relation to psychosexual and physical care for girls and women living with FGM and referral programs for them. The paired sample t-test carried showed a significant increase in knowledge among participants in psychosexual and physical care for girls and women living with $F G M(f=9.25, d f=1, P=.001)$, Psychosexual skills $(f=-8.20, d f=1, P=.001)$, and FGM victims referral Programs $(t=12.95, d f=1, P=.001)$. Follow-up test also showed that these changes were constant from post-test to follow-up.

Conclusions: Preparing the social workers on the integration of physical and psychosocial care for girls and women living with FGM in their existing activities would equip them in providing holistic care for them in addressing the emerging psychosexual problems.

\section{Plain English Summary}

Despite the high prevalence of female genital mutilation in many settings and the health consequences associated with it, many healthcare providers have limited knowledge of female genital mutilation and limited skills for preventing and managing related complications. With Knowledge of this Important matter aim of this study is to determine the effectiveness of TOT workshops on the knowledge and skills of social workers working with girls and women affected by FGM. It is performed on young girls and causes short-term and life-long consequences for women as well as extended consequences for couples, families, and the community at large. These consequences increase the burden on the psychosexual systems. physical and psychosexual care interventions are among the prominent forms of care that can help FGM victims and prevent the practice of FGM. Our research revealed that these interventions were effective in increasing the knowledge of participants. In conclusion, physical and psychosexual care interventions have the potential to prevent FGM/C. They can produce a sustainable impact on the reproductive health and wellbeing of FGM victims. The findings from this study imply that, with caution, physical and psychosexual care interventions can be effectively implemented in different populations of health care providers for FGM victims. 


\section{Introduction}

Female genital mutilation (FGM), also called female genital cutting, involves the partial or total removal of external female genitalia or another injury to the female genital organs for non-medical reasons [1]. FGM is usually performed with a blade or a shard of glass by an elderly person or a midwife with limited training and often in unsanitary conditions [2]. FGM is associated with various health consequences and even death. The practice can result in pain, bleeding, infection, and urinating problems as immediate health consequences. Chronic infections, cysts, chronic pain, birth complications, and sexual and emotional suffering are examples of long-term consequences of FGM [2-4].

FGM is a common practice in Iraqi Kurdistan, an independent region in northern Iraq that includes the three provinces of Erbil, Suleimaniya, and Duhok. In the early 2010s, the prevalence was found to be $40 \%$, varying by geographic location and governorate from $4 \%$ in Dohuk to $58 \%$ in Erbil.

FGM/C provides no health benefits and causes serious immediate and long-term physical, psychological and sexual harm, including chronic pain, recurrent urinary and vaginal infections, post-traumatic stress, and severe pain during sexual intercourse [10]. The immediate effects of FGM (significant pain and heavy bleeding) recur and are often exacerbated during and after childbirth, especially in women with type III FGM [10]. Girls and women who are living with FGM shared the difficulties they had physically with childbirth, enjoying sexual relations, with menstruation, but also the many emotional difficulties [11]. The negative effects of FGM also affect men, many complain of their wives being unable to enjoy sex and the strain this puts on a marriage [12].

The girls and women who live with FGM need care and protection, especially in a crisis-stricken country like Iraq, which is facing various problems where Where due to cultural and religious diversity social problems are high and varied in nature [13-15]. The girls and women who live with FGM have the right to live a life without pain and health, to live without stress, to enjoy sex, ensure physical, psychological, and sexual health will lead to care and protection. Mental health and sexual health are also two of the major aspects similar to physical care and protection. Therefore, the need to promote and practice knowledge and skill-based psychosexual care to girls and women who live with FGM is essential.

In the current study, an 18 days TOT workshop was conducted for the social workers working with FGM victims through the NGOs at Iraqi Kurdistan and reach out to social workers in these towns and villages to discuss and give them tools on how to live with the emotional and physical consequences of FGM. The module was divided into six sections: Understanding female genital mutilation (FGM) and FGM in Iraqi Kurdistan, communicating with girls \& women living with FGM, Immediate \& short-term physical complications arising from FGM, Mental health \& FGM, Sexual health \& FGM and Additional considerations for work with girls and women living with FGM. The module was divided into six sections: (1) Understanding female genital mutilation (FGM) and FGM in Iraqi Kurdistan, (2) Communicating with girls \& women living with FGM, (3) Immediate \& short-term physical complications arising from FGM, (4) Mental health \& FGM, (5) Sexual health \& FGM and (6) Additional considerations for work with girls and women living with FGM. These models look at the care of girls \& women living with FGM by addressing 
their issues at individual, family, and community levels towards making it a clinical care and support model. The current training focused on understanding and addressing issues of FGM victims at the individual level through physical and psychosexual care for FGM victims, rehabilitation intervention, and promoting intervention through clinical care programs and referral programs.

\section{Methodology}

Hamraz counseling center associated with Wadi an association for crisis assistance and development co-operation working with FGM victims across Iraqi Kurdistan through sponsorship and education programs to train the social workers in physical and psychosexual care for FGM victims. The NGO is directly working with 300 villages and cities in Dohuk, Erbil and Solaimaniya through social workers mobile teams. The aim of the program is to incorporate care for FGM victims in their regular activities as well as in the villages and cities, thereby enhancing the psychosexual health of FGM victims through social workers.

The present research was a Quasi-experimental study with a pre-test/post-test control group design. The statistical population included all social workers who worked with violence victims in Iraqi Kurdistan, for the year 2021.

\section{Population, Sample, and Sampling Procedure}

The study sample was selected based on the random sampling method. Inclusion criteria were willingness to participate in the study and history of work with FGM victims as a social worker. Exclusion criteria were unwilling to participate in the study. According to the research methodology, the statistical sample consisted of 44 social workers, selected using the Morgan table by convenience sampling among eligible social workers who had willing to participate in the study. Then they were randomly assigned to the intervention and control groups (22 per group). The Ethical Review Board of the Regional Welfare Organization approved the research.

\section{Living with FGM scale (LWFGM)}

The tools used to collect data were LWFGM Continuum scale developed by the researcher was used to assess the knowledge level of the participants on care of girls and women living with female genital mutilation. The scale can be used by teachers, volunteers, social workers, health workers etc. 21 Items of this scale were designed on a 5-point Likert-type scale, from 0 , indicating that the participant had lower level of Knowledge about the care of girls and women living with FGM, to 4, indicating that the participant had higher level of Knowledge about the care of girls and women living with FGM. The questionnaire requires participants to go through all the ten statements in each set (psychosexual and physical care, psychosexual skills and referral programs) given in it and mark their knowledge. Pilot implement of this scale reported Cronbach's alpha coefficients of .72, .77, and .70 for the subscales of Psychosexual and physical care, psychosexual skills, and referral Programs. They also found the test-retest reliability of 
$.77, .89$, and .85 for the subscales of Psychosexual and physical care, psychosexual skills, and referral Programs, respectively. Descriptive and inferential statistics were carried out for the analysis.

\section{Procedure for Care of girls and women living with FGM}

Care of girls and women living with FGM program consists of six components: Understanding female genital mutilation (FGM), Communicating with girls \& women living with FGM, Immediate \& short-term physical complications arising from FGM, Gynaecological \& urogynaecological care, Mental health \& FGM, Sexual health \& FGM, and Referral program. To implement the six aforementioned programs, the selected participants were randomly assigned to the experimental and control groups, first. The LWFGM scale was administered to both groups as a pretest. Next, the experimental group was given CBT during eight 120-min sessions (two sessions per month, for a total duration of 9 months). The control group, however, received no intervention. After eighteen sessions, the LWFGM scale was administered to both groups, as a post-test this time. Furthermore, the two groups received third administration of the test, as a follow-up measurement to examine the sustainability of changes in behaviors, 1 month later. The obtained data were then statistically analyzed using the SPSS.18 statistical software. It should be noted here that, in an attempt to adhere to ethical principles, the control group also received the treatment after the completion of this study. It is also noteworthy that the intervention program was run by the present researchers. Table 1 presents summaries of the training sessions.

Table 1

Summary of care of girls and women living with FGM Sessions

\begin{tabular}{|c|c|}
\hline Sessions & Contents \\
\hline $\begin{array}{l}\text { Session 1- } \\
2\end{array}$ & $\begin{array}{l}\text { Introduction, FGM in Iraqi Kurdistan and Understanding female genital mutilation } \\
\text { (FGM) }\end{array}$ \\
\hline $\begin{array}{l}\text { Session 3- } \\
5\end{array}$ & Communicating with girls \& women living with FGM \\
\hline $\begin{array}{l}\text { Session 6- } \\
7\end{array}$ & $\begin{array}{l}\text { Immediate \& short-term physical complications } \\
\text { arising from FGM }\end{array}$ \\
\hline $\begin{array}{l}\text { Session 8- } \\
11\end{array}$ & $\begin{array}{l}\text { Gynaecological \& urogynaecological care, Caring for women with FGM during } \\
\text { pregnancy, labour, } \\
\text { childbirth \& postpartum and Deinfibulation }\end{array}$ \\
\hline $12-14$ & Mental health \& FGM \\
\hline 15-17 & Sexual health \& FGM \\
\hline 18 & Referral program and Additional considerations \\
\hline
\end{tabular}

\section{Results}


The results of the assessment on socio demographic variables and the knowledge gain the areas of psychosexual care, physical care and FGM victims and rehabilitation programs and student enrichment program was assessed. Results are given in Table-2.

Table-2: Socio demographic details of participants.

\begin{tabular}{|llll|}
\hline Socio demographic details & N & $\%$ \\
\hline \multirow{3}{*}{ Education } & Under graduate & 24 & 54.5 \\
\cline { 2 - 4 } & Post graduate & 16 & 36.3 \\
\cline { 2 - 4 } & Diploma & 4 & 9.09 \\
\hline \multirow{3}{*}{ Occupation } & Social worker & 20 & 45.5 \\
\cline { 2 - 4 } & Counselor/Psychologist & 24 & 54.5 \\
\hline
\end{tabular}

Out of 44 participants from Wadi (NGO), 44 participants who completed the pre and post assessment were included in analysis. All the participants were female and the mean age was 34.05 . The average year of work experience with children was 8.55. Educational qualification of the participants showed that majority were under graduate (54.5\%) who had different background in social worker and psychology and $38.5 \%$ had Post graduate degree in social work $(n=18)$ whereas $9.09 \%$ had diploma degree $(n=2)$ Table2.

Table 2 - shows the mean values for the level of knowledge and skills of psychosexual and physical care and referral programs for the experimental and control groups. To determine whether changes in the mean values were statistically significant or not, a MANCOVA was run. Accordingly, the pretest scores were considered as covariates. Prior to running MANCOVA, the Levine test was used to examine whether the assumptions of homogeneity of variance were proved or not. The result was not statistically significant for any of the variables (psychosexual and physical care knowledge: $F=2.65, p>.05$; psychosexual and physical care knowledge skills: $F=2.38, p>.05$; referral program: $F=0.48, p>.05$ ). Therefore, MANCOVA could be run. Furthermore, to study homogeneity of covariance matrices, Box's M test was used. The result was statistically significant ( $M$ Box $=11.00, F=1.56, p>.05)$. Therefore, the variance-covariance matrices of the dependent variables were equal in the two groups. 
Table 3

The Effect of care of girls and women living with FGM on the Level knowledge and skills of psychosexual and physical care and referral programs in Iraqi Kurdistan Social workers.

\section{Descriptive statistics}

\begin{tabular}{|lllll|}
\hline & & Pretest & Posttest & \multicolumn{1}{c|}{$\begin{array}{l}\text { Follow- } \\
\text { up }\end{array}$} \\
\hline Variable & Groups & $M(S D)$ & $M(S D)$ & $M(S D)$ \\
\hline $\begin{array}{l}\text { Knowledge of psychosexual and physical } \\
\text { care }\end{array}$ & Experimental & $8.82(2.10)$ & $18.51(1.19)$ & 19.34 \\
& & & & $(3.21)$ \\
\cline { 2 - 5 } & Control & 11.73 & 10.41 & 10.14 \\
Skills of psychosexual and physical care & Experimental & $09.05(2.31)$ & 18.61 & 18.16 \\
& & $(1.84)$ & $(2.06)$ & $(2.60)$ \\
\cline { 2 - 5 } & Control & 11.16 & 11.53 & 11.36 \\
Referral programs & & $(1.33)$ & $(1.85)$ & $(1.27)$ \\
& Experimental & $9.16(2.40)$ & 18.00 & 17.04 \\
& & & $(2.67)$ & $(2.04)$ \\
\cline { 2 - 5 } & Control & 12.66 & 13.58 & 13.27 \\
& & $(1.77)$ & $(2.15)$ & $(1.34)$ \\
\hline
\end{tabular}

MANCOVA results (Table 3) showed a significant difference in the posttest mean scores of the variables of knowledge and skills of psychosexual and physical care and referral programs between the two groups after removing the pretest effect (Wilks's lambda $=0.467 ; F=6.48 ; p<.0001$ ). As one can see from Table 3, the groups were different in level of knowledge and skills of psychosexual and physical care and referral programs. Therefore, based on the descriptive and inferential statistical results, care of girls and women living with FGM was effective in increasing the level of knowledge and skills of psychosexual and physical care and referral programs of social workers.

Table 4

MANCOVA Results for knowledge and skills of psychosexual and physical care and referral programs in Experimental Group and Control Group in Post-test.

\begin{tabular}{|llllll|}
\hline Dependent variable & $\begin{array}{l}\text { Sum of } \\
\text { squares }\end{array}$ & $\begin{array}{l}\text { Degrees of } \\
\text { freedom }\end{array}$ & $\begin{array}{l}\text { M of sum of } \\
\text { squares }\end{array}$ & $\boldsymbol{F}$ & Significant \\
\hline $\begin{array}{l}\text { Knowledge of psychosexual } \\
\text { and physical care }\end{array}$ & 30.85 & 1 & 30.85 & 9.35 & .001 \\
$\begin{array}{l}\text { Skills of psychosexual and } \\
\text { physical care }\end{array}$ & 21.45 & 1 & 21.45 & 8.20 & .001 \\
\hline Referral programs & 59.79 & 1 & 59.79 & 12.95 & .001 \\
\hline
\end{tabular}

In addition, follow-up measurement was performed and MANCOVA was run to investigate differences between the groups in levels of the relevant variables. To this end, prior to running MANCOVA, the Levine 
test was used to examine if the assumptions of homogeneity of variance were proved. The results were not statistically significant for any of the variables (Knowledge of psychosexual and physical care: $F=$ $0.924, p>.05$; Skills of psychosexual and physical care: $F=1.23, p>.05$; Referral Program: $F=0.417, p>$ .05); therefore, MANCOVA could be run. In addition, to examine the homogeneity of covariance matrices, Box's $M$ test was performed. The result was not statistically significant ( $M$ Box $=11.00, F=1.56, p>.05$ ). Accordingly, the variance-covariance matrices of the dependent variables were equal in the two groups.

MANCOVA results (Table 4) showed a significant difference in the level of knowledge and skills of psychosexual and physical care and referral programs between the two groups after removing the pretest effect (Wilks's lambda $=0.489 ; F=5.92 ; p<.0001$ ). Table 4, on the results of follow-up measurement, shows that there have been significant differences between the groups in severity of knowledge and skills of psychosexual and physical care and referral programs after controlling for the effect of the pretest.

Table 5

MANCOVA Results for knowledge and skills of psychosexual and physical care and referral programs in Experimental Group and Control Group in Post-test.

\begin{tabular}{|llllll|}
\hline Dependent variable & $\begin{array}{l}\text { Sum of } \\
\text { squares }\end{array}$ & $\begin{array}{l}\text { Degrees of } \\
\text { freedom }\end{array}$ & $\begin{array}{l}\text { M of sum of } \\
\text { squares }\end{array}$ & $\boldsymbol{F}$ & Significant \\
\hline $\begin{array}{l}\text { Knowledge of psychosexual } \\
\text { and physical care }\end{array}$ & 41.49 & 1 & 41.49 & 9.04 & .001 \\
$\begin{array}{l}\text { Skills of psychosexual and } \\
\text { physical care }\end{array}$ & 38.33 & 1 & 38.33 & 7.68 & .001 \\
\hline Referral programs & 42.20 & 1 & 42.20 & 6.31 & .001 \\
\hline
\end{tabular}

\section{Discussion}

The main objective of this study was to investigate the effect of care of girls and women living with FGM program on increasing the level of knowledge and skills of psychosexual and physical care and referral programs of social workers in Iraqi Kurdistan. The result revealed that the use of care of girls and women living with FGM program led to an increase the levels of knowledge and skills of psychosexual and physical care and referral program of the participants.

Training methodology included lectures, group discussion, activity, show videos, case analysis, etc. The methodology will be beneficial to retain participants' attention and break the monotony of sessions thereby capturing the attention of participants and ensuring their interest to gain knowledge through different activities and practice the same in their work.

The 18 days' workshop was divided into three parts, first and second training focused on psychosexual and physical care for girls and women living with FGM. The topics covered were bio-psycho-sexual health, the impact of FGM on girls and women, techniques for physical and psychosexual care for girls and women, working with girls and women living with FGM using psychological services, and spectrum 
of psychosocial support. These sessions aimed to educate the participants on the curative aspects of psychosexual and physical care that will help to reduce the vulnerability of victims in different conditions.

The third and fourth training focused on the psychosexual skills education for girls and women living with FGM are essentials for the day and nightlife and individual psychosexual ability to adaptive and positive behavior (17-19). The core psychosexual skills education for girls and women living with FGM were addressed in the Third and fourth training ( 6 sessions) as its importance and significance in overall development of children is well explained by Cottingham et al (20) and the preventive intervention will further support girls and women to address the various FGM complications positively.

The FGM victim's referral program covered areas such as study-related referral problems, factors affecting referral, good refer, motivating victims to go near others, eliminating referral barriers, assertiveness, group study, the exam for a talk with other experts, were included in the fifth and sixth training sessions (six sessions) aiming at the developing services and achievement in social workers work. The need for holistic care for girls and women living with FGM is well reported in various studies carried out in similar areas (21-24).

The study revealed that enrich knowledge among social workers who would further train the community level workers and directly impart physical and psychosexual services for girls and women living with FGM and effective in reaching out to them in various accepts to improve the bio-psycho-sexual development and bringing in positive changes in personal, interpersonal, family, and community through the direct intervention by community-level social workers by similar studies (25-28). Imparting knowledge to the grass-root social workers and reaching out to the unreached FGM population is the focus of the stop FGM project that will be achieved by training the social workers through this program.

\section{Conclusion}

The current study on the efficacy of training of trainers to impart knowledge for social workers working with girls and women living with FGM showed positive results in improving knowledge among the master trainers in major three areas of curative, preventive, and referral services in care for girls and women living with FGM. The knowledge and skills gained by the social workers from Wadi will be transferred to other community-level workers at the grass-root level with girls and women living with FGM. That will enable the services reaching to the unreached population thereby supporting FGM victims to ensure and enhance their health.

\section{Declarations}

\section{Acknowledgements}

Harpreet Sihre (HS) checked the screening of the identified papers and the extracted data for accuracy.

\section{Funding}


This study was not directly funded by any external body.

\section{Availability of data and materials}

Interested parties can obtain all available data by contacting the corresponding author.

\section{Authors' contributions}

OM undertook the research, carried out the thematic synthesis and wrote the manuscript and participated in the design of the research and revised the manuscript. Author agreed the final version of the manuscript.

\section{Ethical approval and consent to participate}

Ethical approval was obtained before the start of the project non-governmental organizations with longstanding experience in Iraq as well as in the Kurdistan Region. Moreover, each participant was informed about the procedure and purpose of the study, potential risks and discomforts, the voluntariness of the participation, legal rights, and financial compensation before the start of the interview.

\section{Competing interests}

The author declare that he has no competing interests.

\section{Publisher's Note}

Springer Nature remains neutral with regard to jurisdictional claims in published maps and institutional affiliations. Author details 1, Hamraz Counseling Center, Javanrud, Kermanshah, Iran.

\section{References}

1. World Health Organization. Eliminating female genital mutilation: an interagency statement.Geneva: WHO; 2008. [Google Scholar]

2. Klein E, Helzner E, Shayowitz M, Kohlhoff S, Smith-Norowitz TA. Female genital mutilation: health consequences and complications-a short literature review. Obstet Gynecol Int. 2018; 2018:7365715. doi: 10.1155/2018/7365715. [PMC free article][PubMed] [CrossRef] [Google Scholar]

3. Bjälkander O, Bangura L, Leigh B, Berggren V, Bergström S, Almroth L. Health complications of female genital mutilation in Sierra Leone. Int J Womens Health. 2012;4(1):321.

doi: 10.2147/IJWH.S32670. [PMC free article][PubMed] [CrossRef] [Google Scholar]

4. Berg RC, Underland V, Odgaard-Jensen J, Fretheim A, Vist GE. Effects of female genital cutting on physical health outcomes: a systematic review and meta-analysis. BMJ Open. 2014;4(11):e006316. doi: 10.1136/bmjopen-2014-006316. [PMC free article][PubMed] [CrossRef] [Google Scholar]

5. Shabila N. Geographical variation in the prevalence of female genital mutilation in the Kurdistan region of Iraq. East Mediterr Health J. 2019;25(9):630-6. 
6. Yasin BA, Al-Tawil NG, Shabila NP, Al-Hadithi TS. Female genital mutilation among Iraqi Kurdish women: a cross-sectional study from Erbil City. BMC Public Health. 2013;13:809.

7. Saleem RA, Othman N, Fattah FH, Hazim L, Adnan B. Female genital mutilation in Iraqi Kurdistan: description and associated factors. Women Health. 2013;53:537-51.

8. Iraqi Multiple Indicator Cluster Survey 2018. Final report. Baghdad: Central Statistics Organization and Kurdistan Regional Statistics Ofce; 2019.

9. World Health Organization WHO guidelines on the management of health complications from female genital mutilation. Geneva: World Health Organization; 2016. [Google Scholar][Ref list]

10. WADI Final Report. Stop FGM Middle East. Frankfurt am Main, Germany: WADI; 2014. Available from: http://www.stopfgmmideast.org/wp-content/uploads/2015/01/Report-Stop-FGM-Dec-2014public.pdf (accessed 1 June 2018)

11. Mahmoudi O, Hosseini E. Psychosexual Complications of Female Genital Mutilation for Couples: A Comparative Study, J Kermanshah Univ Med Sci. 2017; 20(4): e69660. doi: 10.22110/jkums.v20i4.2769.

12. Elnashar A, Abdelhady R. The impact of female genital cutting on health of newly married women. International Journal of Gynecol Obstet. 2007;97(3):238-44. 10.1016/j.ijgo.2007.03.008 [PubMed] [CrossRef] [Google Scholar]

13. Stop Violence Against Women: New law criminalizing female circumcision in Iraq. http://www.stopvaw.org/New_Law_Criminalizing_Female_Genital_Mutilation_in_Iraq.html. Accessed 10 March 2020.

14. Shabila NP. Mothers' factors associated with female genital mutilation in daughters in the Iraqi Kurdistan Region. Women Health. 2017;57(3):283-294.

doi: 10.1080/03630242.2016.1164274. [PubMed] [CrossRef] [Google Scholar]

15. Abolfotouh SM, Ebrahim AZ, Abolfotouh MA. Awareness and predictors of female genital mutilation/cutting among young health advocates. Int J Womens Health. 2015;7:259-269. doi: 10.2147/IJWH.S78664. [PMC free article][PubMed] [CrossRef] [Google Scholar]

16. WHO Guidelines on the Management of Health Complications from Female Genital Mutilation. Geneva: World Health Organization; 2016. Executive summary.Available from: https://www.ncbi.nlm.nih.gov/books/NBK368490/

17. Abdulcadir J, Dugerdil A, Boulvain M, Yaron M, Margairaz C, Irion O, Petignat P. Missed opportunities for diagnosis of female genital mutilation. Int J Gynecol Obstet. 2014;125:256-260. doi: 10.1016/j.ijgo.2013.11.016. [PubMed] [CrossRef] [Google Scholar]

18. Balogun OO, Hirayama F, Wariki WMV, Koyanagi A, Mori R. Interventions for improving outcomes for pregnant women who have experienced genital cutting. Cochrane Database Syst Rev. 2013;(2). Art. No.: CD009872. doi:10.1002/14651858.CD009872.pub2. [PMC free article][PubMed]

19. Costello S, Quinn M, Tatchell A, Jordan L, Neophytou K. In the best interests of the child: preventing female genital cutting (FGC) Br J Soc Work. 2015;45(4):1259-1276. doi: 10.1093/bjsw/bct187. [CrossRef] [Google Scholar] 
20. Cottingham J, Kismodi E. Protecting girls and women from harmful practices affecting their health: are we making progress? J. Gynaecol. Obstet. 2009;106(2):128-131.

doi: 10.1016/j.ijgo.2009.03.024. [PubMed] [CrossRef] [Google Scholar]

21. Dustin M. Female genital mutilation/cutting in the UK: challenging the inconsistencies. Eur J Women's Stud. 2010;17:7. doi: 10.1177/1350506809350857. [CrossRef] [Google Scholar].

22. Esmée Fairbairn Foundation (2013) Tackling Female Genital Mutilation in the UK: What works in community-based prevention work, London.

23. Liao LM, Elliott F, Ahmed F, Creighton SM. Adult recall of childhood female genital cutting and perceptions of its effects: a pilot study for service improvement and research feasibility. J Obstet Gynaecol. 2013; 33:292-295. doi: 10.3109/01443615.2012.758695. [PubMed] [CrossRef] [Google Scholar]

24. Moore K. Female Genital Mutilation and Cultural Competency: Moving towards improved management of obstetric care, unpublished Msc thesis.Edinburgh: Queen Margaret University; 2014. [Google Scholar]

25. Shell-Duncan B. From health to human rights: female genital cutting and the politics of intervention. Am Anthropol. 2008;110(2):225-236. doi: 10.1111/j.15481433.2008.00028.x. [CrossRef] [Google Scholar]

26. Whitehorn, J, Ayonrinde, 0 \& Maingay, S (2002) Female genital mutilation: cultural and psychological implications, Sexual and Relationship Therapy, Vol.17:2.

27. Woodward A, Howard N, Wolffers I. Health and access to care for undocumented migrants living in the European Union: a scoping review. Health Policy Plan. 2014;29(7):818-830. doi: 10.1093/heapol/czt061. [PMC free article][PubMed] [CrossRef] [Google Scholar]

28. Zenner N, Liao LM, Richens Y, Creighton SM. Quality of obstetric and midwifery care for pregnant women who have undergone female genital mutilation. J Obstet Gynaecol. 2013;33:459-462. doi: 10.3109/01443615.2013.767785. [PubMed] [CrossRef] [Google Scholar] 